\title{
X-Band Interferometric SAR Observations of Baltic Fast Ice
}

\author{
Anders Berg, Patrik Dammert, Senior Member, IEEE, and Leif E. B. Eriksson, Member, IEEE
}

\begin{abstract}
Detailed mapping of fast-ice deformation can be used to characterize the rheological behavior of fast ice and subsequently improve sea ice modeling. This study uses interferometric synthetic aperture radar to map fast-ice deformation with unprecedented spatial resolution (meter range) and sensitivity (cm-mm range). Two interferometric acquisitions, each with a temporal baseline of $24 \mathrm{~h}$, were performed by the X-band SAR satellite constellation Cosmo-SkyMed over the northeast Bay of Bothnia in the middle of the 2012 ice season. The first interferogram shows deformation of the fast ice due to force from impinging drift ice, and the normal strain within the fast ice is measured. Complementary intensity correlation measurements reveal a slow movement of the drift ice toward the fast ice. The second interferogram exhibits a low fringe rate over the fast ice with fringes being aligned along the coastline. Deformation appears to be stronger around leads, skerries, and grounded ice ridges. It is also observed that the coherence images provide information that is complementary to the information in the backscatter images.
\end{abstract}

Index Terms-Displacement measurement, interferometry, rheology, sea ice, synthetic aperture radar (SAR).

\section{INTRODUCTION}

$\mathbf{I}$ NTERFEROMETRIC synthetic aperture radar (InSAR) is a radar technique that is used to generate maps of surface deformation or elevation [1]. By differentiating the phase of two or more SAR images, one can detect movements along the radar line-of-sight with a precision typically on the order of a fraction of a wavelength.

Interferometric studies of landfast sea ice, or fast ice, are rare, and more studies may advance the understanding of smallscale ice dynamics and contribute to the modeling of sea ice mechanics. A pilot study used C-band SAR data acquired by the ERS-1 satellite to map fast-ice deformations in the northern Baltic Sea [2]. The study also established a connection between backscatter and interferometric coherence over certain ice types and investigated the viscous characteristics of the fast ice in two pressure events. The InSAR technique has been also used with L-band data to map the fast-ice edge in the Arctic coastal system [3]. A high degree of coherence, typically above 0.8 ,

Manuscript received July 3, 2013; revised January 4, 2014 and May 28, 2014; accepted June 28, 2014. This work was supported by the Swedish National Space Board. SAR data were provided by the Italian Space Agency under Contract L/066/09/0 with CSK AO Project ID 2183.

A. Berg and L. E. B. Eriksson are with the Department of Earth and Space Sciences, Chalmers University of Technology, 41296 Gothenburg, Sweden (e-mail: anders.berg@chalmers.se).

P. Dammert is with the SAAB Electronic Defence Systems (EDS), 41289 Gothenburg, Sweden.

Color versions of one or more of the figures in this paper are available online at http://ieeexplore.iee.org.

Digital Object Identifier 10.1109/TGRS.2014.2336752 was achieved with the temporal baseline of 46 days offered by the Japanese ALOS satellite.

Until now, no study has used spaceborne SAR at the X-band for fast-ice repeat-pass interferometry. The high frequencies of the X-band theoretically provide capability to map small-scale fast-ice deformations with unprecedented resolution and sensitivity. The shorter wavelengths increase the sensitivity to lineof-sight displacements and further reduce the detection limit for small displacements. Finer spatial resolution is beneficial as it facilitates the detection of leads and ridges and allows for clearer mapping of minor deformation zones, for example, around small islands. Moreover, the coherence measured with repeat-pass SAR may be regarded as a remote sensing observable that can infer information about various surficial processes [4]. Considering fast ice, the information content provided by the temporal coherence is not well known.

This study uses the Italian X-band SAR satellite constellation Cosmo-SkyMed to investigate deformation and displacement of Baltic fast ice. The Baltic Sea is a semienclosed brackish sea in Northern Europe. The northernmost section of the Baltic Sea is the Bay of Bothnia. Here, the fast ice develops along the coast early in the ice season, normally with the start in late November. With support from the shoreline, skerries (rocky islands or reefs), and grounded deep ice ridges, it grows bit by bit in a stepwise manner [5]. The outer edge of the fast ice is limited by the water depth and does not extend beyond depths of 5-15 $\mathrm{m}$ where the ice is subject to much larger dynamic forces [6]. Looking at the vertical scale, level fast ice in the Bay of Bothnia often consists of two layers: a top layer that contains snow ice or superimposed ice and a bottom layer of frazil ice formed during turbulent conditions in supercooled water [7]. The salinity of the fast ice in the Bay of Bothnia is very low, i.e., beneath 0.5 , and decreases with depth. As a comparison, the salinity of fully-grown first-year fast ice in the Canadian Archipelago has been measured to an average of 4 throughout the ice [8]. The fast ice in the Baltic Sea normally endures the whole ice season and dissolves by rotting and breaking down during the melting period, which typically occurs in May.

The X-band SAR data were used to generate interferograms with spatial resolution in the meter range and show sea ice deformation and displacement on the order of centimeters. The interferograms reveal that the fast ice, despite its definition as stationary ice, is subject to noticeable deformation and internal fraction. We also study the interferometric coherence and find that it is possible to obtain high coherence images with the temporal baseline of $24 \mathrm{~h}$. Furthermore, we see that the coherence images provide information that is complementary to the information obtained from backscatter images over areas of fast ice. 
TABLE I

SumMARY OF SAR AND WEATHER PARAMETERS

\begin{tabular}{lcc}
\hline & Image pair A & Image pair B \\
\hline Acq. dates & $2012-03-15$ & $2012-03-31$ \\
Local time (CET) & $2012-03-16$ & $2012-04-01$ \\
Orbit & $18: 59$ & $04: 12$ \\
Look direction & Descending & Ascending \\
Inc. angle ${ }^{1}$ & Right & Left \\
Slant range ${ }^{1}$ & $29.4^{\circ}$ & $46.2^{\circ}$ \\
Normal baseline & $717 \mathrm{~km}$ & $873 \mathrm{~km}$ \\
Critical baseline & $102 \mathrm{~m}$ & $56 \mathrm{~m}$ \\
Height of ambiguity ${ }^{1}$ & $4.3 \mathrm{~km}$ & $6.5 \mathrm{~km}$ \\
\hline Air temperatures ${ }^{2}$ & $49 \mathrm{~m}$ & $160 \mathrm{~m}$ \\
First acq. & & \\
Min. btw. acq. & $0^{\circ} \mathrm{C}$ & $-16^{\circ} \mathrm{C}$ \\
Max. btw. acq. & $0^{\circ} \mathrm{C}$ & $-17^{\circ} \mathrm{C}$ \\
Second acq. & $5^{\circ} \mathrm{C}$ & $-1{ }^{\circ} \mathrm{C}$ \\
Wind speed and direction $^{2}[\mathrm{~m} / \mathrm{s}]$ & $5{ }^{\circ} \mathrm{C}$ & $-15^{\circ} \mathrm{C}$ \\
Mean betw. acq. & & \\
First acq. & $6 \mathrm{SSW}$ & $1-$ \\
Second acq. & $5.7 \mathrm{~S}$ & $1.5 \mathrm{NNE}$ \\
\hline${ }^{1}$ Values at mid-swath & $5.1 \mathrm{~W}$ & $1.0 \mathrm{SW}$ \\
${ }^{2}$ Weather at Kemi-Tornio Airport & &
\end{tabular}

\section{Geographical Setting And SAR Image Data}

The images used in this study cover a region in the northeast Bay of Bothnia. The images were acquired in March and April of 2012 by two Cosmo-SkyMed satellites. Two interferometric acquisitions were made in strip-map mode (product known as himage) with a temporal baseline of $24 \mathrm{~h}$. Important SAR and interferometric parameters are listed in Table I. Horizontal polarization was used for transmission and reception. The scenes cover an area of $40 \times 40 \mathrm{~km}$ and have a spatial resolution of $3 \times$ $3 \mathrm{~m}$ (ground range versus azimuth). The processing scheme used for interferometric processing of the images is outlined in [23].

We use the daily ice charts published by the Swedish Ice Service at the Swedish Meteorological and Hydrological Institute [9] as a reference for ice type classification. The classification is made by sea ice analysts and based on prevailing and historical ice conditions. The fast ice is identified as the ice that remains fast along the coast. There was no change in the location of the fast-ice edge during the study period.

The first image pair, hereinafter denoted as image pair A, was acquired on March 15 and 16, 2012, at 18:59 local time (CET), with a normal (perpendicular) baseline of $102 \mathrm{~m}$ and an incidence angle of about $30^{\circ}$. The first image of this pair is shown in Fig. 1. The scene covers the fast ice off Kemi and Tornio in Finland. The fast ice is mostly confined to the archipelago in the north and is $35-60 \mathrm{~cm}$ thick. The ice conditions are more varied south of the fast ice, where the ice is classified as very close pack ice and has a reported thickness of $40-65 \mathrm{~cm}$. The pack ice includes an area of ridged ice, located off the fast ice on the west side of the scene. The ridged ice area started to take form almost two months earlier and slowly grew larger as winds were pushing the ice northward. The southeast region consists of level pack ice with somewhat thinner ice, between 30 and $60 \mathrm{~cm}$. The temperature was around $0{ }^{\circ} \mathrm{C}$ during the first acquisition and increased to $5{ }^{\circ} \mathrm{C}$ on the second day [10]. There were light snow showers in the area in the evening of March 15. The average wind speed between the acquisitions was $6 \mathrm{~m} / \mathrm{s}$ with southerly to southwesterly winds.

Fig. 2 shows the first image of the second image pair, i.e., image pair B, which was acquired on March 31 and April 1, at 04:12 local time. The normal baseline was $56 \mathrm{~m}$, and the incident angle was $45^{\circ}$ at the scene center. The scene covers the same area as for image pair A, but from an ascending orbit instead of a descending orbit. Two weeks after image pair A was acquired, the ice conditions essentially remained unchanged. The mean air temperature during the two weeks was $-3{ }^{\circ} \mathrm{C}$, although some very cold nights at the end of the period may have caused a small growth in the ice thickness. The temperature was $-16{ }^{\circ} \mathrm{C}$ as the first image was acquired on March 31 . Afterward, it rose to $-1{ }^{\circ} \mathrm{C}$ during the day and then decreased to $-15{ }^{\circ} \mathrm{C}$ as the second acquisition took place on April 1. The average wind speed during the $24 \mathrm{~h}$ between the acquisitions was $1 \mathrm{~m} / \mathrm{s}$. The wind direction was variable, starting with northerly winds that turned southwest and eventually back north.

The sea level is another observable with an impact on the interferometric measurement. A change in sea level affects the range according to $\Delta R=\phi / 2 k$, where $\phi$ is the interferometric phase, and $k$ is the wavenumber. There are two oceanographic stations with tide gauges in the Bay of Bothnia that provided sea level data during the study period [11]. These are located near Kalix on the north shore of the bay and at Ratan in the Kvarken sound that forms the southern bound of the bay. The placement of the stations is such that the horizontal variations in sea level can be resolved [12]. The temporal variability in sea level is fairly slow with respect to the sampling frequency of $1 \mathrm{~h}$. For image pair A, the water level in Kalix rose from 26 to $27 \mathrm{~cm}$ from the first acquisition to the second, whereas in Ratan, it rose from 14 to $18 \mathrm{~cm}$. Between the image acquisitions of pair $\mathrm{B}$, a rise from -10 to $-6 \mathrm{~cm}$ was measured at the Kalix station, and the sea level at Ratan rose from -6 to $-4 \mathrm{~cm}$. Thus, the maximum relative change in sea level was $3 \mathrm{~cm}$, and with a distance between the stations of around $220 \mathrm{~km}$, the corresponding relative change in sea level within one scene (of about 40-km length) was about $5 \mathrm{~mm}$.

Table I also includes the height of ambiguity, which is the amount of elevation variation corresponding to an interferometric phase change of one fringe $(2 \pi)$ [1]. The height of ambiguity characterizes the sensitivity to changes in topographic height. For the flat Baltic fast ice, the effect from topography is insignificant. A typical ice ridge with a sail height of $1 \mathrm{~m} \mathrm{[13]}$ would only produce an interferometric phase change of $7^{\circ}$ and $2^{\circ}$ in pairs A and B, respectively.

\section{Coherence Images}

Coherence $\gamma(u, v)$ is a measure of the quality of the interferometric phase difference and is defined as [14]

$$
\gamma=\frac{\mathbf{E}\left\{a \cdot b^{*}\right\}}{\sqrt{\mathbf{E}\left\{|a|^{2}\right\} \mathbf{E}\left\{|b|^{2}\right\}}}, \quad 0 \leq|\gamma| \leq 1
$$




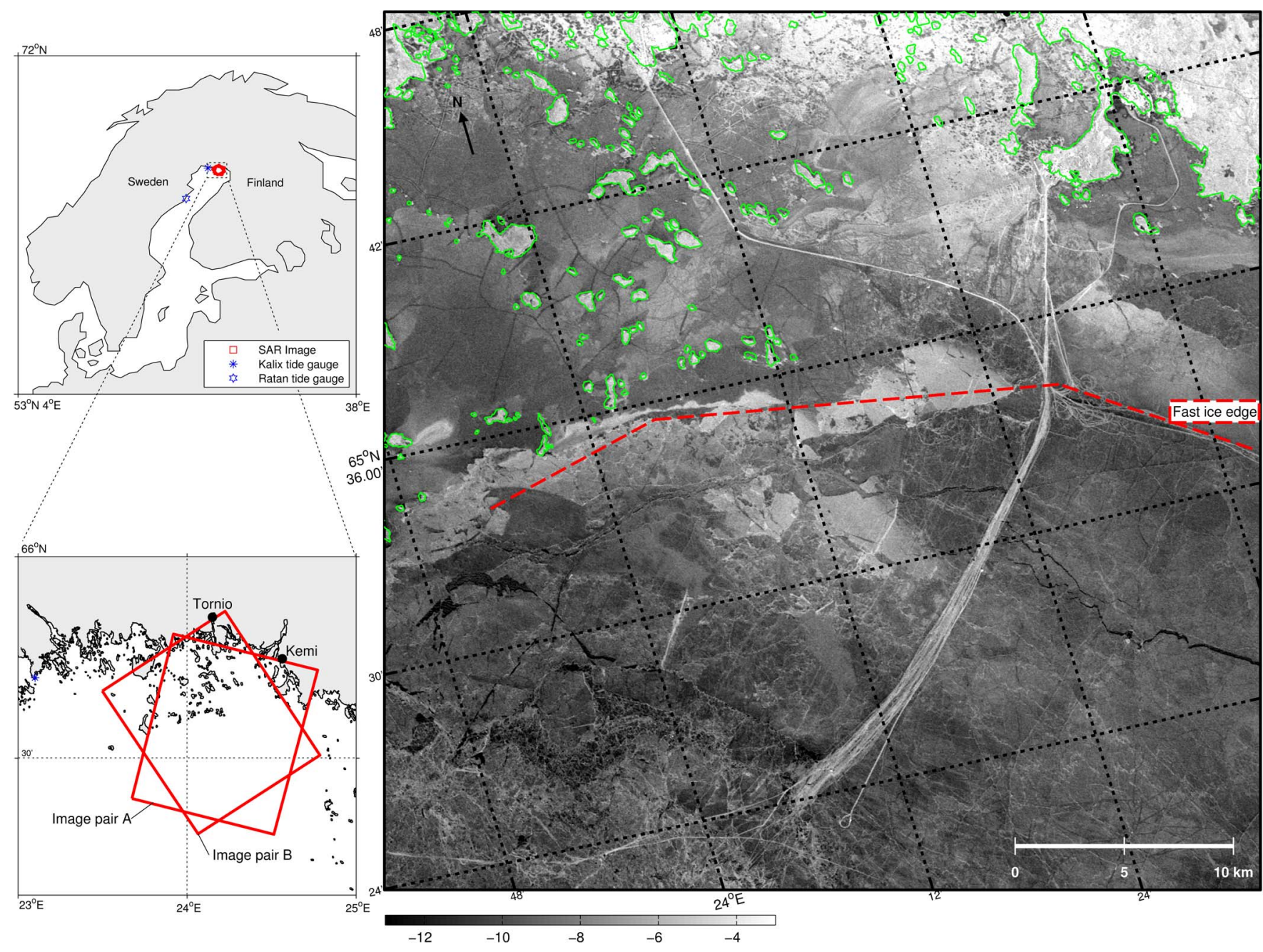

Fig. 1. Upper-left panel shows an overview of the Baltic Sea. The lower-left panel shows an enlargement of the study region and the geometry of both image pairs. The large panel shows image 1 of pair A, from March 15, 2012, with backscatter values in decibels. The shoreline is shown in green color. The approximate location of the fast-ice edge is also shown. (COSMO-SkyMed Product—ASI—Agenzia Spaziale Italiana—2012. All Rights Reserved.)

between SAR image $a$ and $b$ at pixel $(u, v)$. The $(u, v)$ arguments have been dropped for brevity in (1). $\mathbf{E}\{y\}$ denotes the expectation value of function $y$. The coherence can be expressed as a product of three factors [4], i.e.,

$$
\gamma=\gamma_{\text {thermal }} \cdot \gamma_{\text {spatial }} \cdot \gamma_{\text {temporal }}
$$

The factor $\gamma_{\text {thermal }}$ is due to thermal noise in the receiver and can be determined from the signal-to-noise ratio (SNR). The radar signal is measured as scattering coefficient $\sigma_{0}$, and the sensitivity of the SAR system is determined by the upper limit of the noise equivalent $\sigma_{0}$. For the Cosmo-SkyMed satellites, this system parameter has been specified to $-19 \mathrm{~dB}$ [15]. Contrasting this value to the fast-ice backscatter coefficient of $-11 \mathrm{~dB}$ (measured from our data), the coherence factor due to thermal noise can be approximated by $\gamma_{\text {thermal }}=1 /(1+$ $\left.\mathrm{SNR}^{-1}\right) \approx 0.9$. The second decorrelation factor, i.e., $\gamma_{\text {spatial }}$, characterizes decorrelation due to perspective changes caused by the spatial baseline. The spatial decorrelation is determined by the length of the normal baseline relative the critical baseline [16]. Following a mathematical formalism in [16] together with the baseline information in Table I, it can be inferred that $\left|\gamma_{\text {spatial }}\right| \geq 0.97$. The remaining factor $\gamma_{\text {temporal }}$ stands for physical changes in the surface. While the two other factors are stable and have a magnitude relatively close to $1, \gamma_{\text {temporal }}$ is the major cause of decorrelation and the principal quantity we measure. The factor describes, for example, decorrelation due to ice drift or random changes in scatterer positions within a resolution cell.

The degree of coherence (hereinafter referred to as coherence) of image pair A is shown in Fig. 3. Relatively high coherence can be observed over islands and along the edge of the fast ice. There is also one section of the fast ice that has high coherence, which is visible in the southwest corner of the image.

The other parts of the image show low coherence, typically with values below 0.3 . There are several factors that may have contributed to the low coherence. To begin with, the light snowfall that occurred between the image acquisitions may be one factor. Another factor, which certainly holds true in the south part of the image, is that the ice movement is too large with respect to the wavelength. Last but not least, one must consider the temperature increase from $0{ }^{\circ} \mathrm{C}$ to $5{ }^{\circ} \mathrm{C}$. As the air temperature increases, so does the moisture in the surface layer. When the upper snow layer becomes wet, scatterers within this 


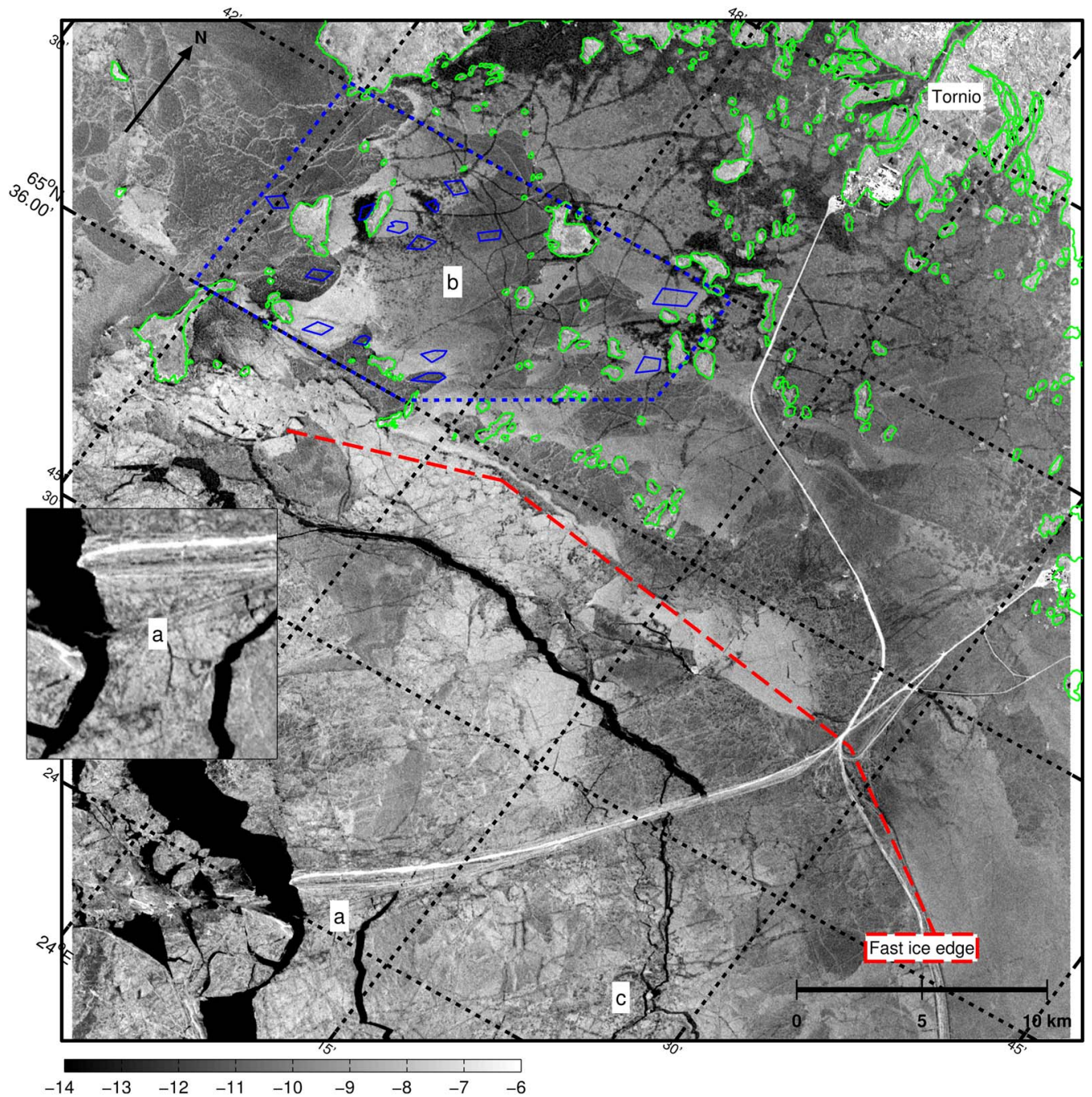

Fig. 2. Image 1 of pair B, from March 31, 2012, with backscatter values in decibels. The shoreline is shown in green color. The approximate location of the fast-ice edge is also shown. The embedded panel shows an enlargement of area $a$. Areas $a$ (lead), $b$ (fast-ice regions in blue polygons), and $c$ (shallow) are discussed in the text. (COSMO-SkyMed Product—ASI—Agenzia Spaziale Italiana—2012. All Rights Reserved.)

layer will dominate the returned signal. This situation is consistent with a noticeable change between the two backscatter images. The subsurface layers become less significant to the scattering, which results in an overall reduction of contrast in the second image. Many fine details such as ridges and cracks have become fainter.

The coherence of image pair B is shown in Fig. 4. The figure shows that the coherence is high over most parts of the scene and significantly higher than the coherence of image pair A. Apart from one ice floe that drifted several meters, the ice has not moved more than the coherence can be maintained. The inner parts of the fast ice show somewhat lower coherence, potentially due to snow melting and refreezing. It is interesting to note that the open channels toward the harbors appear very clearly with low coherence and, at the same time, difficult to identify in the backscatter images (see Fig. 2, area $a$ ). The effect is most clearly seen by the entrance to the channels where the backscatter image brings out the older refrozen leads with very high backscatter, and the open lead is almost hidden. The open leads are characterized by their low coherence, which could be explained by the presence of open water or broken brash ice within the channels. Open water decorrelates within tens of milliseconds [1], but decorrelation would likewise occur for brash ice, particularly if the ice is stirred by ship traffic. One may also note that the backscatter inside the lead is higher than in between the ice floes off the fast ice, which is reasonable if the open leads contain brash ice.

Another aspect of the coherence image that is noticeable is the coherence fluctuations over both the fast ice and the pack ice. It seems like the coherence level is related to ice type and may be used to characterize the surface in a similar way as for the backscatter image. To see how the coherence relates to the backscatter, a number of homogeneous (in backscatter as well as coherence) regions were selected in the fast ice within the archipelago to make statistical measurements. The regions were selected in area $b$ (see Fig. 2), with areal sizes of $0.4 \mathrm{~km}^{2}$ on average. The result is plotted in Fig. 5, where the backscatter has been measured in image 1 of image pair B. The backscatter was stable between the acquisitions, and the interrelationships between the regions did not change, although there was an overall increase of $0.75 \mathrm{~dB}$ (possibly within calibration inaccuracies; cf. [17]). 


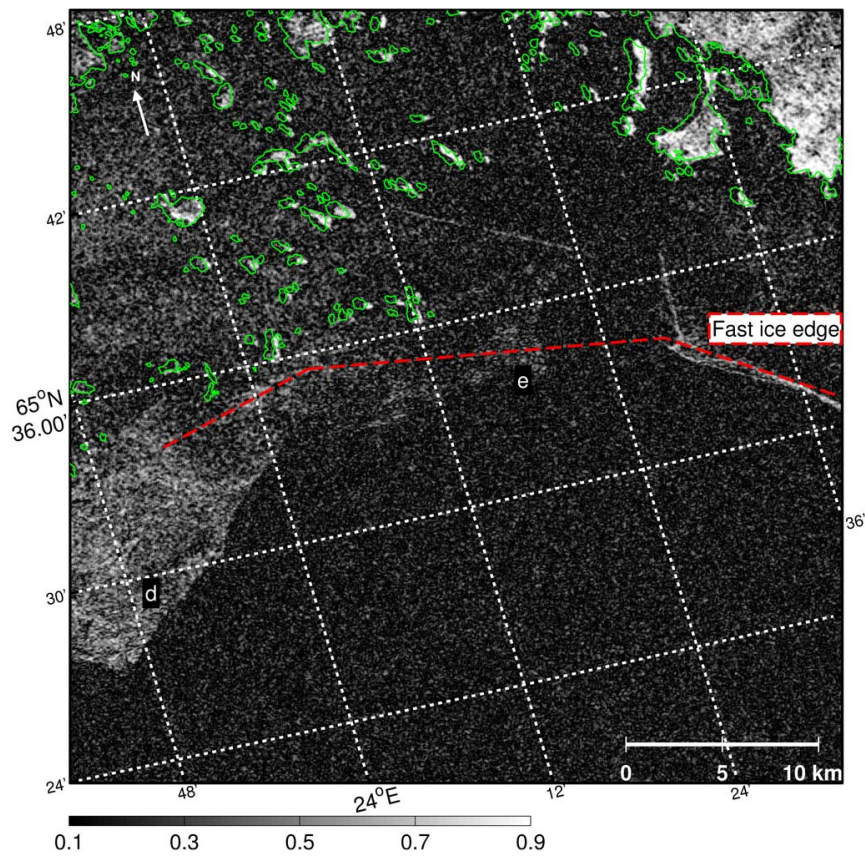

Fig. 3. Degree of interferometric coherence for image pair A. Black is lowest coherence (0.1), and white is highest coherence (0.9). The shoreline is shown in green color. Areas $d$ (ice patch) and $e$ (compressed ice) are discussed in the text.

Three of the regions deviated from this trend and showed no change or a decrease of up to $0.5 \mathrm{~dB}$. One may also note (in Fig. 5) that the coherence is very low, i.e., below 0.2 , in these regions. For other regions with the same level of backscatter, the coherence is much higher. There is no apparent explanation for the low coherence, which nearby regions did not show; however, further examination can bring some clarity. Evidently, a physical process occurred between the two image acquisitions that either changed the electromagnetic properties of the scattering elements or stirred their position. The texture of the backscatter in these regions was found to become somewhat mottled in the second image. At least two possibilities exist: 1) The three regions could have become flooded, for example, through thermal cracks, holes, brine, or other intercrystalline channels in the ice [18]. Slush or snow ice would then form on the ice surface, the absorption would increase, and a drop in coherence would be expected. 2) Snow properties and scatterers in the snow volume may have changed due to melting. It is possible that the air temperature reached above zero degrees during the day. The temperature in Kemi peaked at $-1{ }^{\circ} \mathrm{C}$ in the shade, and higher temperatures could have occurred in sun-exposed areas. The solar radiation can induce subsurface melting, increasing snow moisture and, thereby also, the absorption of the radar signal [19]. The effect would be that less radiation is reflected by the snow ice layer, giving a decrease in the measured backscatter. On the other hand, the temperature is very cold during the image acquisitions, and the snow cover can be expected to be dry and easily penetrated by the incoming radiation.

Returning to Fig. 5, one may observe a trend toward higher coherence for higher backscatter for coherence values above 0.2. An opposite trend is observed in [2], using C-band data, in nearby and partly overlapping regions. The result could possibly be explained by differences in weather between the two studies, but there were no diametrical differences in weather. The absence of field data makes it difficult to investigate factors such as surface roughness and snow layer, which are known to have a large impact on the backscattering. One may speculate that the dominating scatterer differs between the two cases, such that scatterers in the ice/water interface matters most at the C-band, whereas scatterers in the air/ice surface have the largest impact at the X-band. The difference in penetration depth at the C-band and the X-band would in that case be decisive. The penetration depth is determined by the complex dielectric constant $\epsilon$ [20], which, in turn, can be estimated from the brine volume $V_{b}$. For sea ice in the Bay of Bothnia, we may use the dielectric model from [21] and adopt the modification for lowsaline ice in [22] to arrive at the following model for the X-band $(10 \mathrm{GHz})$ :

$$
\begin{aligned}
\epsilon^{\prime} & =3.0+12 V_{b} \\
\epsilon^{\prime \prime} & =0.001+10 V_{b}
\end{aligned}
$$

for the real and imaginary parts, respectively. Measurements of ice cores from the area of interest [7] suggest a typical brine volume of $1 \%$, which would generate a penetration depth of nearly $10 \mathrm{~cm}$ at the $\mathrm{X}$-band. Considering that the ice thickness is more than $40 \mathrm{~cm}$ (from the ice chart) and the incidence angle is around $46^{\circ}$, the power transmitted to the ice/water interface will be insignificant. A brine volume less than $0.25 \%$ is required to increase the penetration depth down to the water. By applying the dielectric model in [22] for the C-band ( $5 \mathrm{GHz})$, it can be seen that the penetration depth is approximately five times deeper than for the X-band. This result strengthens the hypothesis that scattering from the ice/water interface could be dominant in [2].

\section{INTERFEROGRAMS}

The interferograms produced from the two image pairs are presented in Figs. 6 and 7. The first interferogram is affected by the low coherence, which is why the interferometric phase could not be determined everywhere. The most prominent feature in the first interferogram is the dense fringes on the fast ice along the west side of the scene (area $d$ in Fig. 6). The structure of the interferogram in the patch, such as the decline in fringe rate in the north direction, allows us to conclude that the movement is horizontal. A change in the absolute sea level, for example, will not show up in the interferogram because the fast ice is afloat, and the ice level changes along with sea level. The ice will be displaced, but there will not be any differential movement apart from locations where the ice is grounded. A change in sea level tilt may however have an effect on the measurement. In this case, the change is too small to explain the dense fringes, as the relative change in sea level of $5 \mathrm{~mm}$ over the whole scene corresponds to a change in radar line-of-sight of roughly $4 \mathrm{~mm}$, or about one fourth of a fringe. In this case, when the fringes are aligned very close with the across-track direction and due to the fact that the radar measures only the slant range component, the ice patch must be subject to shear stress.

The pack ice in the south has moved over several resolution cells between the acquisitions. The translation can be estimated 


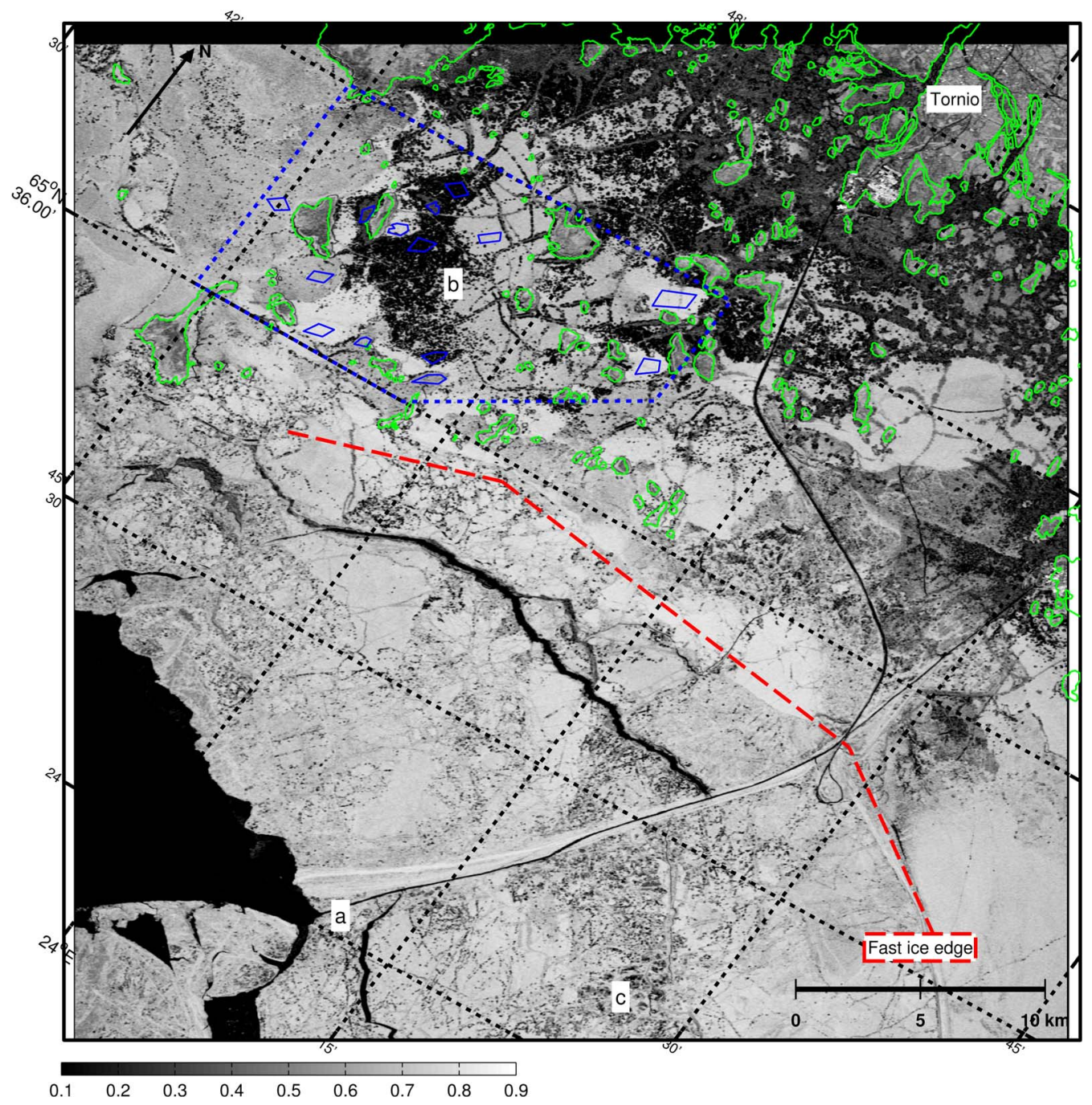

Fig. 4. Degree of interferometric coherence for image pair B. Black is lowest coherence (0.1), and white is highest coherence (0.9). The shoreline is shown in green color. Areas $a$ (lead), $b$ (fast-ice regions in blue polygons), and $c$ (shallow) are discussed in the text.

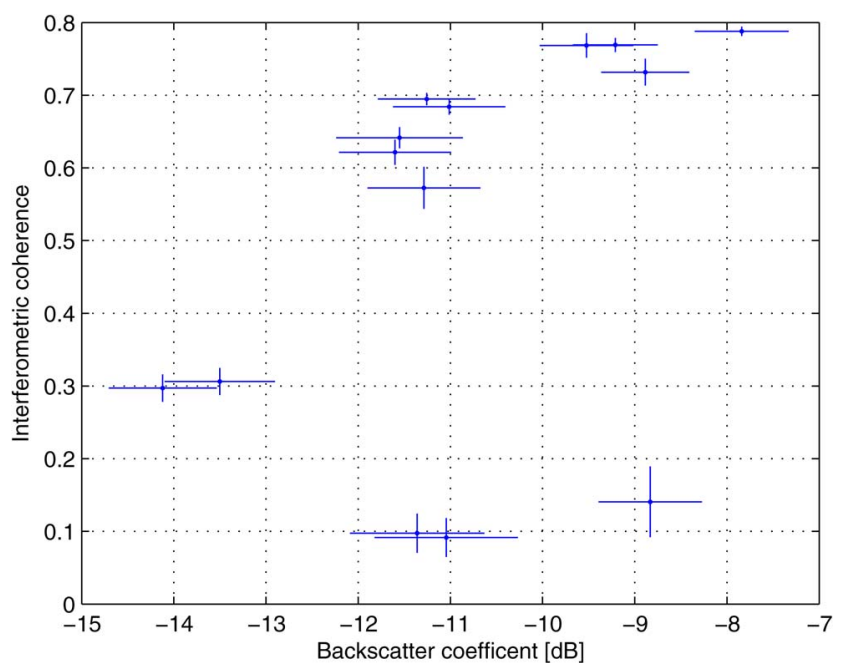

Fig. 5. Backscatter coefficient versus interferometric coherence for a number of regions selected within the fast ice (area $b$ in Fig. 2) in image pair B. The image from March 31 was used for backscatter measurement. The intersection points represent the mean values, and the lines show the standard deviation. by cross-correlating the two images. The images are divided into smaller windows, which are correlated to each other to obtain their relative offset. The computation can be made in the frequency domain, and the technique is then known as phase correlation (see, e.g., [24]). By using this tracking technique on the images, the result in Fig. 8 was obtained. One may observe an overall drift toward northeast, which is in agreement with the dominating wind direction. It appears as the drift ice has been pushing toward the fast ice, which is in line with the presumed compression that can be observed, for example, in the very center of the scene.

The interferogram made from image pair B shows a general movement away from the coast with higher deformation around islands and close to leads. It shows a rather low fringe rate over the fast ice with fringes being aligned along the coastline. The same appearance can be observed in the ice that is attached to the fast ice. A few alternative interpretations of the fringe pattern have been identified and will be listed as follows: 1) The differential motion may be explained by a sea level tilt in the east-west direction but is highly unlikely due to lack of strong winds. 2) The ice may be subject to horizontal deformation 


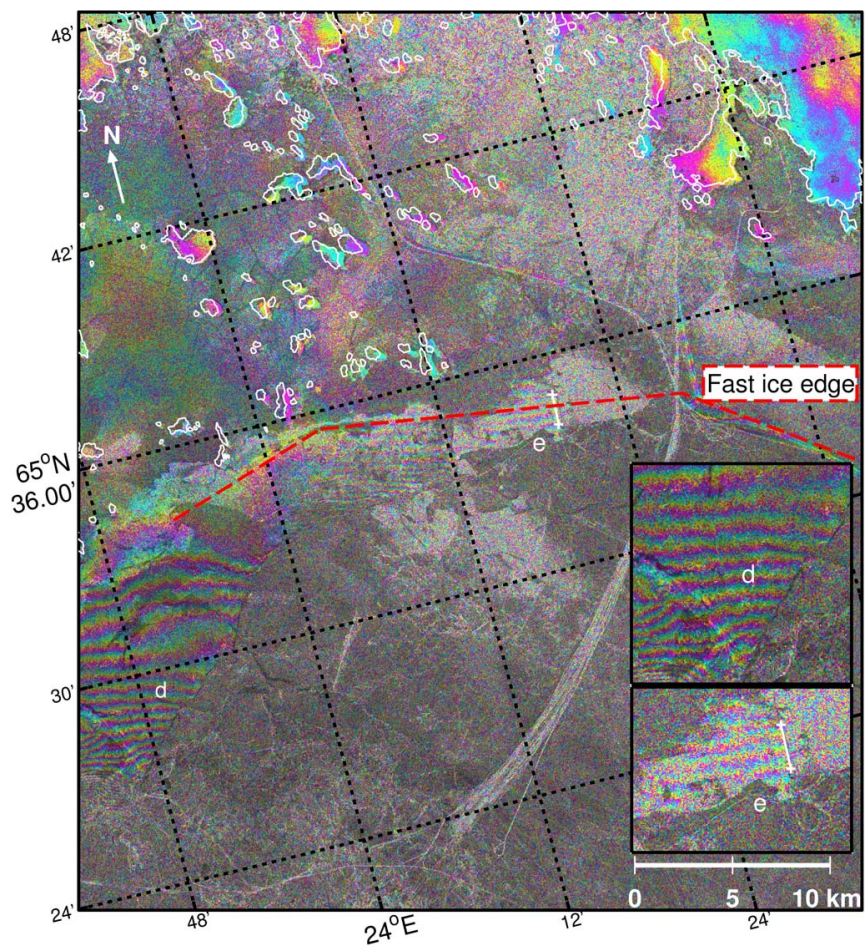

Fig. 6. Flattened interferogram produced with image pair A, on top of backscatter image from March 15, 2012. One fringe corresponds to a displacement of $\lambda / 2$, or $1.56 \mathrm{~cm}$, in the direction of the radar. The saturation of the color is scaled by the level of coherence. Enlarged areas $d$ (ice patch) and $e$ (compressed ice) are discussed in the text. The location of the compression measurement (white line in area $e$ ) is also shown.

due to water stresses. In this case, the water would exert a dragging force on the ice in the offshore direction. The drag force would be caused by surface currents from river inlets. The two rivers named Torne River and Kemijoki empty in the region, $30 \mathrm{~km}$ apart from each other. What weighs against this explanation is that the free drifting ice in the southwest is almost lying still. There is therefore no indication of under-ice currents. 3) Possibly the most likely explanation can be ascribed to thermal expansion in the ice-a mechanism described, e.g., in [25]. Low-saline ice expands with increasing temperature at temperatures beneath about $-5{ }^{\circ} \mathrm{C}$ [26]. Although the air temperatures were comparable at the time of the satellite flyovers, heat could have been transferred to the ice during the day when the air temperature was much higher. By counting fringes over the ice patch in the southern edge of the image (parallel to the lead), the deformation was found to correspond to an expansion in the ground plane of $6.5 \mathrm{~cm}$ over a distance of $10 \mathrm{~km}$. This expansion would be generated by a relative decrease in density of $2 \cdot 10^{-5}$. From [26], it can be inferred that the density of low-saline ice decreases with temperature in a nearly linear relationship with slope $1.6 \cdot 10^{-4} \mathrm{~kg} / \mathrm{m}^{3} / \mathrm{K}$ at ice temperatures below $-5{ }^{\circ} \mathrm{C}$. This leads to the conclusion that the ice temperature would need to have increased by $0.12{ }^{\circ} \mathrm{C}$ to give the purported expansion.

Fig. 7 shows a local circular deformation in the southeast part of the image (location $c$ in Fig. 2). Studying the bathymetry on a nautical chart, it appears that the location is very shallow with depths down to $1.0-1.2 \mathrm{~m}$. The conclusion is therefore that the fast ice was grounded in this location. As the ice thickness

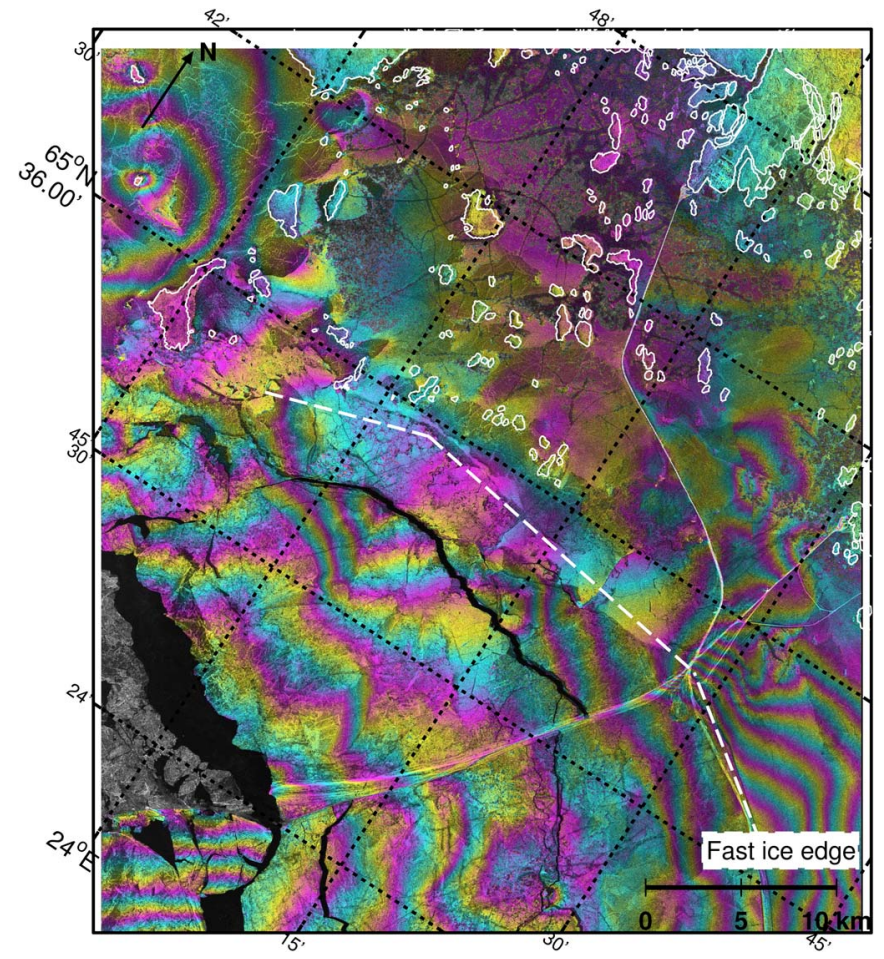

Fig. 7. Flattened interferogram produced with image pair B, on top of backscatter image from March 31, 2012. One fringe corresponds to a displacement of $\lambda / 2$, or $1.56 \mathrm{~cm}$, in the direction of the radar. The saturation of the color is scaled by the level of coherence.

here is not more than $60 \mathrm{~cm}$, based on the ice chart, and the water level was normal, the grounded ice must be ridged. The interferogram indicates that the surrounding ice decreased in height to a lower level. It is not probable that the ridged ice increased in height because that would imply drastic changes in the scattering geometry with formation of new scatterers, and with that would follow a significant decrease in coherence.

\section{A. Ice Rheology}

Following Hibler's viscous-plastic rheology [27], Dammert et al. in [2] were able to measure the strain in a patch of fast ice in the Bay of Bothnia and use it to determine the bulk viscosity of the ice. The forces on the ice patch were associated to wind and water currents, with a small contribution also from sea surface tilt. The fast-ice compression was found to be properly described by linear viscous rheology, which means that the stress is directly proportional to the strain rate.

In our case, we may have a closer look at the compression in the center of the interferogram generated from image pair A (area $e$ in Fig. 6). The ice patch is located at the edge of the fast ice. Just off the fast ice, there is a region of drift ice that moved approximately $100 \mathrm{~m}$ toward the fast ice, as shown in Fig. 8. The drift ice appears to be tightly connected to the fast ice, and presumably, it exerted a pressure force upon the fast ice, causing it to compress. The fast ice may have been dragged by wind forces as well. The compression of the patch was measured by counting the number of fringes over a distance normal to the fast-ice edge (shown in Fig. 6), starting from the edge. The relative movement along the radar line-of-sight 


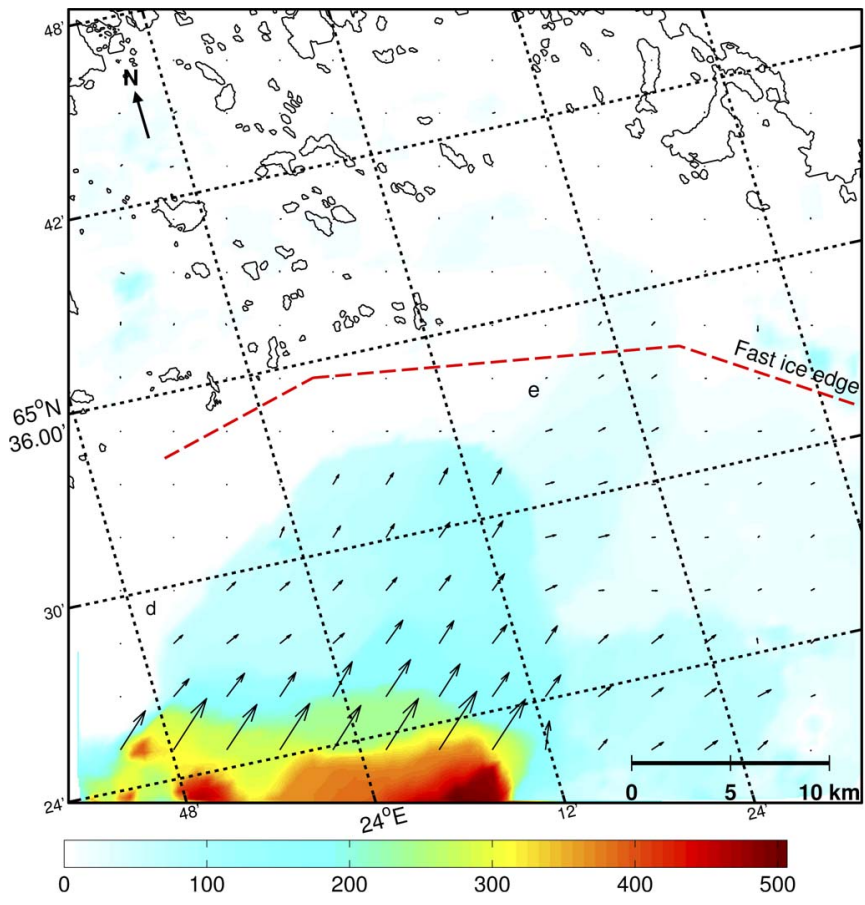

Fig. 8. Map showing ice displacement computed from areal correlation of image pair A, which has a temporal separation of $24 \mathrm{~h}$. The color indicates the translation in meters, and the arrows show the (relative) magnitude and direction of the drift.

direction was measured to 3 fringes over a distance of $1800 \pm$ $25 \mathrm{~m}$. The direction of the movement was estimated from the alignment of the fringes, to $12 \pm 2^{\circ}$ off the azimuth direction in the ground range plane. Assuming normal stress, the resulting compression becomes $46 \pm 10 \mathrm{~cm}$, which infers a strain of $\epsilon=(2.6 \pm 0.5) \cdot 10^{-4}$. This value can be compared with the strain measured in [2], which was about $5 \cdot 10^{-5}$, or a factor 4 lower. With similar weather conditions and ice thickness in our study, it suggests that wind and water currents solely cannot produce the high compression. It is instead likely that the higher strain is due to the force exerted by the impinging drift ice.

\section{CONCLUSION}

Under favorable conditions, X-band SAR interferometry provides detailed information on fast-ice deformation. The interferograms reveal interesting phenomena, such as a deformation of the fast-ice edge under pressure from drift ice. The highfrequency band makes it possible to detect movement on the order of $1 \mathrm{~cm}$. The high sensitivity comes with some limitations. The temporal baseline needs to be short to maintain high coherence. The appropriate length of time depends on how fast temporal decorrelation occurs; however, the study shows that it is possible to obtain high coherence with a baseline of $24 \mathrm{~h}$, although one interferometric acquisition showed lower coherence than the other. The lower coherence may be attributed to precipitation and temperature variations or, potentially, to effects from wind. A longer temporal baseline would be necessary to provide the ability to separate fast ice from drift ice with InSAR, simply because drift ice may be motionless for a period of one or two days. A second option is to collect a longer time series of interferometric images, which would also make it possible to detect long-term trends in deformation. Moreover, it would be valuable to perform two interferometric acquisitions over the same scene, from different directions, to obtain two components of the surface movement. This can be realized by acquiring images from descending and ascending orbits. Overall, from this study, it can be concluded that X-band SAR interferometry is a useful tool for mapping small-scale fast-ice deformations under favorable weather conditions.

The coherence images provide information that is complementary to information from backscatter images. One example is the open channels that appear very clearly as lines with low coherence in the coherence images but which are not visible in the backscatter images. It may also be concluded that the backscatter and coherence levels are connected in certain regions, indicating a change of either the scatterer geometry or the permittivity within specific ice types. The interpretation of coherence images is not trivial and would benefit from in situ measurements, preferably carried out at each satellite passage and with continuous observations in the period in-between.

\section{ACKNOWLEDGMENT}

The authors would like to thank W. Dierking from the Alfred Wegener Institute for the useful discussion and comments on the manuscript.

\section{REFERENCES}

[1] R. Bamler and P. Hartl, "Synthetic aperture radar interferometry," Inv. Prob., vol. 14, no. 4, pp. R1-R54, 1998.

[2] P. Dammert, M. Leppäranta, and J. Askne, "SAR interferometry over Baltic Sea ice," Int. J. Remote Sens., vol. 19, no. 16, pp. 3019-3037, 1998.

[3] F. J. Meyer et al., "Mapping Arctic landfast ice extent using L-band synthetic aperture radar interferometry," Remote Sens. Environ., vol. 115, no. 12, pp. 3029-3043, Dec. 2011.

[4] H. A. Zebker and J. Villasenor, "Decorrelation in interferometric radar echoes," IEEE Trans. Geosci. Remote Sens., vol. 30, no. 5, pp. 950-959, Sep. 1992.

[5] M. Leppäranta, The Drift of Sea Ice. Berlin, Germany: Springer-Verlag, 2011.

[6] M. Leppäranta, On the Structure and Mechanics of Pack Ice in the Bothnian Bay, vol. 248. Helsinki, Finland: Finnish Marine Research, 1981, pp. 3-86.

[7] M. Granskog, H. Kaartokallio, H. Kuosa, D. N. Thomas, and J. Vainio, "Sea ice in the Baltic Sea-A review," Estuarine, Coastal Shelf Sci., vol. 70, no. 1/2, pp. 145-160, Oct. 2006.

[8] B. Holt and S. A. Digby, "Processes and imagery of first-year fast sea ice during the melt season," J. Geophys. Res., vol. 90, no. C3, pp. 5045-5062, May 1985.

[9] Swedish Meteorological and Hydrological Institute, Ice Conditions, Mar./Apr. 2012. [Online]. Available: http://www.smhi.se/klimatdata/ oceanografi/havsis

[10] Weather Underground Inc., Weather History Data, Nov. 2012. [Online]. Available: http://www.wunderground.com

[11] Baltic Operational Oceanographic System, Observations-Waterlevel, Jun. 2013. [Online]. Available: http://www.boos.org

[12] A. Omstedt, "Modelling the Baltic Sea as thirteen sub-basins with vertical resolution," Tellus A, vol. 42, no. 2, pp. 286-301, Mar. 1990.

[13] M. Leppäranta and R. Hakala, "The structure and strength of first-year ice ridges in the Baltic Sea," Cold Regions Sci. Technol., vol. 20, no. 3, pp. 295-311, Jun. 1992.

[14] M. Born and E. Wolf, Principles of Optics: Electromagnetic Theory of Propagation, Interference and Diffraction of Light, 7th ed. Cambridge, U.K.: Cambridge Univ. Press, 1999.

[15] "COSMO-SkyMed SAR products handbook," Rome, Italy, Tech. Rep., 2007.

[16] S. N. Madsen and H. A. Zebker, "Imaging radar interferometry," in Principles and Applications of Imaging Radar, Manual of Remote Sensing, 
vol. 2, F. M. Henderson and A. J. Lewis, Eds. Hoboken, NJ, USA: Wiley, 1998, pp. 359-380.

[17] S. Pettinato, E. Santi, S. Paloscia, P. Pampaloni, and G. Fontanelli, "The intercomparison of X-band SAR images from COSMO-SkyMed and TerraSAR-X satellites: Case studies," Remote Sens., vol. 5, no. 6, pp. 2928-2942, Jun. 2013.

[18] H. Röthlisberger, "Snow and slush on floating lake ice," Ann. Glaciol., vol. 4, pp. 236-240, 1983

[19] M. P. Mäkynen, B. Cheng, M. H. Similä, T. Vihma, and M. T. Hallikainen, "Comparisons between SAR backscattering coefficient and results of a thermodynamic snow/ice model for the Baltic Sea land-fast sea ice," IEEE Trans. Geosci. Remote Sens., vol. 45, no. 5, pp. 1131-1141, May 2007.

[20] F. T. Ulaby, R. K. Moore, and A. K. Fung, Microwave Remote Sensing Active and Passive, vol. II. Norwood, MA, USA: Artech House, 1982, ser. Radar Remote Sensing and Surface Scattering and Emission Theory.

[21] F. Carsey, Microwave Remote Sensing of Sea Ice. Washington, DC, USA: Amer. Geophys. Union, 1992.

[22] A. Carlström and L. Ulander, "Validation of backscatter models for level and deformed sea-ice in ERS-1 SAR images," Int. J. Remote Sens., vol. 16, no. 17 , pp. 3245-3266, Nov. 1995.

[23] C. Werner, U. Wegmüller, T. Strozzi, and A. Wiesmann, "Gamma SAR and interferometric processing software," in Proc. ERS-ENVISAT Symp., Gothenburg, Sweden, 2000, pp. 16-20.

[24] M. Thomas, C. A. Geiger, and C. Kambhamettu, "High resolution $(400 \mathrm{~m})$ motion characterization of sea ice using ERS-1 SAR imagery," Cold Regions Sci. Technol., vol. 52, no. 2, pp. 207-223, Apr. 2008.

[25] L. Bergdahl et al., "Ice mechanics," in River and Lake Ice Engineering, G. Ashton, Ed. Highlands Ranch, CO, USA: Water Resources Publications, 1986, ch. 3, pp. 87-202.

[26] G. Timco and W. Weeks, "A review of the engineering properties of sea ice," Cold Regions Sci. Technol., vol. 60, no. 2, pp. 107-129, Feb. 2010.

[27] W. Hibler, III, "A dynamic thermodynamic sea ice model," J. Phys. Oceanography, vol. 9, no. 4, pp. 815-846, Jul. 1979.

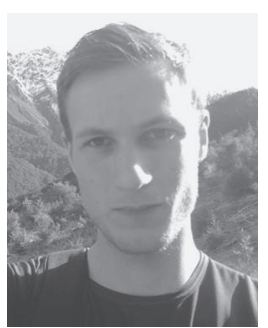

Anders Berg received the M.Sc. degree in engineering physics and the Ph.D. degree from Chalmers University of Technology, Gothenburg, Sweden, in 2008 and 2014, respectively.

He is currently a Postdoctoral Researcher with the Radar Remote Sensing Group, Department of Earth and Space Sciences, Chalmers University of Technology. His research interests include remote sensing of sea ice using spaceborne synthetic aperture radar and radar altimetry.

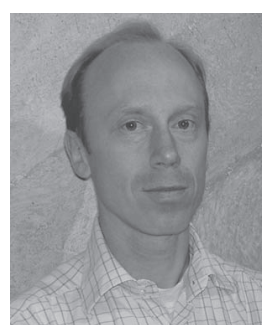

Patrik Dammert (S'95-M'00-SM'07 ) received the M.Sc. degree in electrical engineering and the Ph.D. degree in the applications of spaceborne synthetic aperture radar (SAR) interferometry from Chalmers University of Technology, Gothenburg, Sweden, in 1993 and 1999, respectively.

From 1999 to 2000, he was a Research Assistant with Chalmers University of Technology, prior to joining SAAB Electronic Defence Systems (formerly Ericsson Microwave Systems), where he has since been responsible for the development of high-performance SAR systems for airborne radars, spanning from VHFband to X-band systems (with flat-plate antennas and AESA antennas). $\mathrm{He}$ has been also a project manager and an associate doctoral student supervisor for research projects at SAAB in collaboration with Chalmers University of Technology and Blekinge Institute of Technology, Blekinge, Sweden. His research interests include SAR systems, radar modeling, algorithms and signal processing, autofocus, and target detection in heavy-tailed radar clutter.

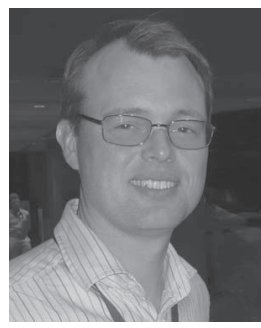

Leif E. B. Eriksson (M'05) received a University Certificate in space technology from Umeå University, Umeå, Sweden, in 1993; the M.S. degree in electrical engineering from Chalmers University of Technology, Gothenburg, Sweden, in 1998; and the Ph.D. degree from Friedrich Schiller University, Jena, Germany, in 2004.

From 1999 to 2000, he was with the Joint Research Centre-European Commission, Space Application Institute, Ispra, Italy, where he was engaged in ERS data for forest and wetland mapping in Siberia. Between 2000 and 2004, he was with the Department of Geoinformatics, Friedrich Schiller University, where he was engaged in C-band and L-band synthetic aperture radar (SAR) interferometry for forestry applications. Since 2004, he has been with the Department of Earth and Space Sciences, Chalmers University of Technology, where, in 2012, he was promoted to Associate Professor in radar remote sensing. His current research interests include the use of SAR for forestry and oceanography applications. 